\title{
CSCL in Asia
}

\author{
Gerry Stahl • Friedrich Hesse
}

Published online: 2 February 2011

(C) International Society of the Learning Sciences, Inc.; Springer Science+Business Media, LLC 2011

\section{Shanghai competes in PISA}

Mainland China participated in 2009 in the PISA (Programme for International Student Assessment) tests for the first time since PISA started to be administered internationally by the OECD in 2000. China was represented by students from Shanghai. Shanghai took first place in all three major categories: reading, science, and mathematics. The PISA tests are given every 3 years to a large sample of 15 -year-old students in over sixty countries. In the recently released results from testing in 2009, generally 5 of the 6 top-placing countries were Asian (see Table 1). With the participating Asian countries all at the top, the United States and most of the European countries (except Finland) were way down in the mediocre world-average range.

Of course, educational researchers may question the significance of standardized testing from many perspectives. In particular, CSCL researchers may wonder if high scores reflect an outmoded individualized drill-and-practice approach of memorizing facts rather than building knowledge collaboratively. Do winning scores result from an oriental Confucian philosophy that accepts traditional ways but will fail at creating innovation in a knowledge society?

Arguing against such suspicions, the OECD report and associated videos (http://www. oecd.org/document/13/0,3343,en_2649_35845621_46538637_1_1_1_1,00.html\#Videos) indicate that Shanghai's success is the result of consciously forward-looking government policies. As quoted in the New York Times, OECD spokesman Andreas Schleicher summarized:

In recent years, teaching has rapidly climbed up the ladder of preferred occupations in China, and salaries have risen. In Shanghai, the authorities have undertaken important curricular reforms, and educators have been given more freedom to experiment.... For

G. Stahl $(\bowtie)$

Drexel University, Philadelphia, PA, USA

e-mail: gerry.stahl@gmail.com

F. Hesse

Knowledge Media Research Center, Tubingen, Germany 
Table 1 The top six countries in the PISA 2009 test scores

\begin{tabular}{lll}
\hline Science & Reading & Mathematics \\
\hline Shanghai & Shanghai & Shanghai \\
Finland & Korea & Singapore \\
Hong Kong & Finland & Hong Kong \\
Singapore & Hong Kong & Korea \\
Japan & Singapore & Taiwan \\
Korea & Canada & Finland \\
\hline
\end{tabular}

me, the real significance of these results is that they refute the commonly held hypothesis that China just produces rote learning.... Large fractions of these students demonstrate their ability to extrapolate from what they know and apply their knowledge very creatively in novel situations. (Dillon 2010)

Perhaps it is time for skeptical CSCL researchers to visit Shanghai and see what is going on there.

\section{Another CSCL conference in Asia}

The CSCL research community began largely in Western Europe and North America. It held its first conferences on those continents. Of course, there were always some Asian researchers involved, but most of them had academic ties to the West. In an effort to become more international, the CSCL community held its first Asian conference in Taipei in 2005, attracting many local scholars and students. Meanwhile, Asia-based conferences like ICCE and its sponsor, APSCE, have become active in presenting CSCL research, largely from Asian labs. This year, the international CSCL conference will return to Asia, hosted by the University of Hong Kong.

The theme of this year's conference ties CSCL research to policy and practice. There will be a variety of events related to educational policy before, during, and after the conference. A special feature will be a chance-of-a-lifetime opportunity to tour Mainland China to learn about educational policy and practice there. From July 11-15, a group of CSCL conference attendees will go to Guangzhou, Shanghai, and Beijing. This series of post-conference activities in Mainland China is an attempt to bring together researchers, practitioners, and policy-makers within China and internationally to identify ways to better leverage the potentials that research on learning and learning technologies bring to educational change and improvement. It is a chance to meet with policy makers, researchers, educators, and classroom teachers; to visit teacher-training universities and primary schools; and to not only observe, but also actually participate in the transformations underway there. See http://www.isls.org/cscl2011/call4post-conf.htm for details.

\section{Asian educational policies}

The irony, it seems, is that while educational policy in the US and many European countries seems increasingly confined to teaching to standardized tests, policies in places like Singapore and Hong Kong are explicitly aiming for " 21 st Century skills," which they 
recognize require transcending rote learning in favor of collaborative knowledge building, computer-supported analysis, and creative thinking. While much of the underlying theory, technology, and research in CSCL originated in the West, current politics there resist the ideological and institutional transformations necessary for widespread implementation. For visionary political initiatives, we may have to look to Asia and to exceptional Western instances like Finland and Canada.

In preparation for the conference in Hong Kong, we feature a report on educational policy, CSCL research, and classroom practice in Singapore in this issue of ijCSCL. In the next issue, we will feature a similar piece on policy, research, and teacher training in Hong Kong.

This issue's opening presentation on the Singapore experience by Chee Kit Looi, HyoJeong So, Yancy Toh \& Wenli Chen is framed in terms of the need to integrate reform efforts at three scales. Building on the discussion of meso-level infrastructure in an early ijCSCL paper (Jones et al. 2006), it distinguishes the micro level of student learning and interaction, the meso level of teacher professional development in the school, and the macro level of national policy and strategic planning. The authors report from the unique position of working within the Learning Sciences Lab of the National Institute of Education at Nanyang Technological University, established by the Singapore Ministry of Education specifically to transform educational practice based on the latest research in the learning sciences. In undertaking this mission, the authors discovered that the research does not provide a clear implementation path for preparing students for the world of the 21 st Century. Rather, they realize that much of the needed educational philosophy was already clear in Dewey's vision of student-centered education for democracy, inquiry, and innovation a century earlier, but that neither he nor his followers have had much effect on the rote-learning focus of an educational system tuned to the industrial age. Change must take place simultaneously on many levels, and this requires a carefully coordinated, phased, and iterative approach. The article chronicles a phased national policy of educational reform, a scalable approach to gradually working with increasing numbers of teachers, and an iterative design-based method of research in the classroom. A central illustration in the paper is the way that a particular CSCL technology, Group Scribbles, was introduced into some Singapore classrooms over several years. It discusses how embedded researchers worked closely with early-adopter teachers to tune the socio-technical system of this software's classroom role, based on analysis of situated student interaction mediated by the technology. A large chart in the article summarizes the coordination over time of design principles, curricular products, technology development, teacher professional development, and the spread of innovation among schools. While Singapore is a unique national system, its educational reform experience seems to offer lessons for other countries around the world.

\section{CSCL research in Singapore}

To complement the presentation on the macro-level effort of the Learning Sciences Lab in Singapore, we include two additional research reports from that lab. Then we publish two other papers on Asian CSCL research. These are not our first Asian papers. In fact, we started in the very first issue of $i j C S C L$ with an article from Hong Kong (Lee et al. 2006) and have published papers from the Asia-Pacific region every year (Baghaei et al. 2007; Hung et al. 2008; Isotani et al. 2009; Kapur and Kinzer 2009; Lu et al. 2010; Oshima et al. 2006; Reimann 2009; Rourke and Kanuka 2007; Tee and Karney 2010; van 
Aalst 2009). IjCSCL is an international journal and aims to publish a high-quality selection of world-class CSCL research from wherever groundbreaking work is taking place.

Manu Kapur's methodological proposal, “Temporality matters," responds to an earlier contribution arguing that "Time is precious" (Reimann 2009) and that CSCL should adopt methods that analyze temporal processes of interaction. Of course, some varieties of interaction analysis do focus on the sequentiality and response structure of dialogical utterances (e.g., Çakır et al. 2009; Schegloff 2007; Suthers et al. 2010). But Reimann and Kapur are not so much looking to qualitatively analyze individual interactions as to be able to quantitatively determine sequential patterns of interactions within a data corpus. Kapur proposes the adoption by CSCL researchers of Lag-sequential Analysis (LsA), a statistical technique used in other fields. This technique is similar to Hidden Markov Modeling (HMM) (Soller and Lesgold 2003) in that it yields transition probabilities that one category of event will follow another category. The paper illustrates with a study of students in India how LsA can provide findings that would be lost to a traditional codingand-counting approach, which aggregates events of each category and hides their respective ordering. Kapur's LsA temporal analysis revealed which groups ordered their problem-solving moves more effectively, providing insight into desirable group knowledge-building processes.

The illustrative study in Kapur's paper involved a phenomenon known as "productive failure." This phenomenon is one of the most interesting findings to come out of CSCL research (see Barron 2003; Kapur and Kinzer 2009; Schwartz 1995). Productive failure is the finding that student groups who score lower on individual post-tests may have actually experienced deeper learning (such as developing more abstract conceptualizations) that could eventually lead to superior performance in the future. A team at the Singapore lab set out to investigate this phenomenon with a qualitative analysis of group processes among physics students. Suneeta A. Pathak, Beumie Kim, Michael J. Jacobson, \& Baohui Zhang set up a situation of productive failure by initially giving some student groups wellstructured problems, which tested for relatively rote learning of physics laws, and giving other groups ill-structured physics problems, which required more innovative thinking. Since the ill-structured problems were more challenging, the groups with them had lower rates of solution, but gained experiences that helped them with later problems. The authors manipulate the conditions systematically and analyze the resultant student interactions carefully. Previous studies of productive failure have focused on quantitative analysis to demonstrate the phenomenon, and have had to merely speculate on the mechanisms at work in the group interactions. This new study conducts qualitative analysis to see what the student groups are actually saying and what forms of shared understanding they are coconstructing. The authors then relate their findings to the notion of scripting in CSCL (Dillenbourg and Hong 2008; Kobbe et al. 2007; Stegmann et al. 2007), suggesting that scripting can be used to take advantage of the hidden learning that occurs with productive failure.

\section{More Asian CSCL research}

In ijCSCL's first paper from Mainland China, Zi-Gang Ge explores issues of a field that is particularly important in Asia: English as a foreign language. This research explores peer review of writing assignments. It takes advantage of computer networking to have students review each other's essays anonymously. In particular, the use of asynchronous, anonymous 
online exchanges was hypothesized to lessen the Chinese cultural aversion to criticizing people face-to-face. An experiment was conducted with engineering students at a university in Beijing. Students were classified based on their English writing ability in order to see which level of student would be helped most by the collaborative intervention. Although there was generally a positive response to the peer-review process by the students, those with lower skills sensed that they were being reviewed by stronger students and often felt inferior, which sometimes increased their determination to improve. The better writers, on the other hand, felt that they were not learning as much from the process because the advice they received was not as good as what they gave. Perhaps engineering students in China are similar to those in the West, who resist collaboration based on their drive to excel as individuals (Rick and Guzdial 2006).

The paper by Michael Glassman \& Min Ju Kang presents the logic of inquirysometimes called "abduction" in contrast to deduction and induction - as discussed by Dewey and Peirce. Rather than arguing from some initial facts or ideas to a single prediction or conclusion, abduction involves exploring multiple possibilities suggested by an observation. The paper then proposes that computer-supported collaboration media like wikis and blogs could be further developed to support such multi-faceted inquiry in classrooms. The collaborative hypertext could provide an alternative to traditional linear and unilateral deductive thinking, such as when a teacher instructs about factual material or elicits predicted information. The technology can support complex networks of knowledge exploration and innovative thinking. The authors, one of whom is from Korea, review student experiences - including students in the Philippines, Japan, Taiwan, and Koreathat take first steps in the kind of student-centered inquiry that Dewey proposed, but was not able to institute in his day. While the paper's ideas hearken back to classic hypertext notions of Engelbart and Nelson in the 1960s, they bring them together with the logic of inquiry as a foundation of Dewey's progressive education. It is not clear why blogs and wikis should be singled out, and not extensions of discussion forums like Knowledge Forum (Scardamalia 2002) or WebGuide (Stahl 2006, Ch. 6). Perhaps, Singapore's experiments with Group Scribbles (Looi, et al., this issue) also illustrate the kind of networking software that can support classroom abduction, while in addition indicating the design-based research that is needed to transform communication technologies into media for effective student knowledge creation (van Aalst 2009).

\section{Another perspective on research}

We conclude this issue by returning most of the way to Europe with a contribution by Baruch B. Schwarz, Yaron Schur, Haim Pensso, \& Naama Tayer about research in Israel as part of a European Union project. This work relates to themes from the preceding papers. In particular, it considers the effort within CSCL to reform education, and the barriers and complexities associated with this effort. Adopting a somewhat different take on the many factors involved, it explores issues involving the teacher role in mediating student collaborative knowledge building and conceptual change. This paper builds on previous studies in this journal by the same lab on computer support for argumentation (Asterhan and Schwarz 2010; Schwarz and De Groot 2007; Schwarz and Glassner 2007). Engaging in multiple controversies within CSCL and using various means of intervention and of analysis, the paper raises issues about how to accomplish the CSCL vision in schools through the coordinated efforts of researchers, teachers, and other stakeholders through a design-based research process similar to that in Singapore. 


\section{References}

Asterhan, C., \& Schwarz, B. (2010). Online moderation of synchronous e-argumentation. International Journal of Computer-Supported Collaborative Learning, 5(3), 259-282. doi:10.1007/s11412-010-9088-2.

Baghaei, N., Mitrovic, A., \& Irwin, W. (2007). Supporting collaborative learning and problem-solving in a constraint-based CSCL environment for UML class diagrams. International Journal of ComputerSupported Collaborative Learning, 2(2), 159-190. doi:10.1007/s11412-007-9018-0.

Barron, B. (2003). When smart groups fail. The Journal of the Learning Sciences, 12(3), 307-359.

Çakır, M. P., Zemel, A., \& Stahl, G. (2009). The joint organization of interaction within a multimodal CSCL medium. International Journal of Computer-Supported Collaborative Learning, 4(2), 115-149. Web: http://GerryStahl.net/pub/ijCSCL_4_2_1.pdf doi:10.1007/s11412-009-9061-0

Dillenbourg, P., \& Hong, F. (2008). The mechanics of CSCL macro scripts. International Journal of Computer-Supported Collaborative Learning, 3(1), 5-23. doi:10.1007/s11412-007-9033-1.

Dillon, S. (2010). Top test scores from Shanghai stun educators. The New York Times. Retrieved December 7, 2010

Hung, D., Lim, K., Chen, D.-T., \& Koh, T. (2008). Leveraging online communities in fostering adaptive schools. International Journal of Computer-Supported Collaborative Learning, 3(4), 373-386. doi:10.1007/s11412-008-9051-7.

Isotani, S., Inaba, A., Ikeda, M., \& Mizoguchi, R. (2009). An ontology engineering approach to the realization of theory-driven group formation. International Journal of Computer-Supported Collaborative Learning, 4(4), 445-478. doi:10.1007/s11412-009-9072-x.

Jones, C., Dirckinck-Holmfeld, L., \& Lindström, B. (2006). A relational, indirect, meso-level approach to CSCL design in the next decade. International Journal of Computer-Supported Collaborative Learning, 1(1), 35-56. doi:10.1007/s11412-006-6841-7.

Kapur, M., \& Kinzer, C. (2009). Productive failure in CSCL groups. International Journal of ComputerSupported Collaborative Learning, 4(1), 21-46. doi:10.1007/s11412-008-9059-z.

Kobbe, L., Weinberger, A., Dillenbourg, P., Harrer, A., Hämäläinen, R., Häkkinen, P., et al. (2007). Specifying computer-supported collaboration scripts. International Journal of Computer-Supported Collaborative Learning, 2(2), 211-224. doi:10.1007/s11412-007-9014-4.

Lee, E., Chan, C., \& van Aalst, J. (2006). Students assessing their own collaborative knowledge building. International Journal of Computer-Supported Collaborative Learning, 1(1), 57-87. doi:10.1007/ s11412-006-6844-4.

Lu, J., Lajoie, S., \& Wiseman, J. (2010). Scaffolding problem-based learning with CSCL tools. International Journal of Computer-Supported Collaborative Learning, 5(3), 283-298. doi:10.1007/s11412-010-9092-6.

Oshima, J., Oshima, R., Murayama, I., Inagaki, S., Takenaka, M., Yamamoto, T., et al. (2006). Knowledgebuilding activity structures in Japanese elementary science pedagogy. International Journal of Computer-Supported Collaborative Learning, 1(2), 229-246. doi:10.1007/s11412-006-8995-8.

Reimann, P. (2009). Time is precious: Variable- and event-centred approaches to process analysis in CSCL research. International Journal of Computer-Supported Collaborative Learning, 4(3), $239-257$. doi:10.1007/s11412-009-9070-z.

Rick, J., \& Guzdial, M. (2006). Situating CoWeb: A scholarship of application. International Journal of Computer-Supported Collaborative Learning, 1(1), 89-115. doi:10.1007/s11412-006-6842-6.

Rourke, L., \& Kanuka, H. (2007). Barriers to online critical discourse. International Journal of ComputerSupported Collaborative Learning, 2(1), 105-126. doi:10.1007/s11412-007-9007-3.

Scardamalia, M. (2002). Collective cognitive responsibility for the advancement of knowledge. In B. Smith (Ed.), Liberal education in a knowledge society. Chicago: Open Court.

Schegloff, E. A. (2007). Sequence organization in interaction: A primer in conversation analysis. Cambridge: Cambridge University Press.

Schwartz, D. (1995). The emergence of abstract representations in dyad problem solving. Journal of the Learning Sciences, 4(3), 321-354.

Schwarz, B., \& De Groot, R. (2007). Argumentation in a changing world. International Journal of Computer-Supported Collaborative Learning, 2(2), 297-313. doi:10.1007/s11412-007-9020-6.

Schwarz, B., \& Glassner, A. (2007). The role of floor control and of ontology in argumentative activities with discussion-based tools. International Journal of Computer-Supported Collaborative Learning, 2(4), 449-478. doi:10.1007/s11412-007-9024-2.

Soller, A., \& Lesgold, A. (2003). A computational approach to analyzing online knowledge sharing interaction. Paper presented at the 11th International Conference on Artificial Intelligence in Education, AI-ED 2003. Sydney, Australia. Proceedings pp. 253-260: Amsterdam: IOS Press.

Stahl, G. (2006). Group cognition: Computer support for building collaborative knowledge. Cambridge: MIT. 
Stegmann, K., Weinberger, A., \& Fischer, F. (2007). Facilitating argumentative knowledge construction with computer-supported collaboration scripts. International Journal of Computer-Supported Collaborative Learning, 2(4), 421-447. doi:10.1007/s11412-007-9028-y.

Suthers, D., Dwyer, N., Medina, R., \& Vatrapu, R. (2010). A framework for conceptualizing, representing, and analyzing distributed interaction. International Journal of Computer-Supported Collaborative Learning, 5(1), 5-42. doi:10.1007/s11412-009-9081-9.

Tee, M. Y., \& Karney, D. (2010). Sharing and cultivating tacit knowledge in an online learning environment. International Journal of Computer-Supported Collaborative Learning, 5(4), 385-414. doi:10.1007/ s11412-010-9095-3.

van Aalst, J. (2009). Distinguishing knowledge-sharing, knowledge-construction, and knowledge-creation discourses. International Journal of Computer-Supported Collaborative Learning, 4(3), 259-287. doi:10.1007/s11412-009-9069-5. 